\title{
Molecular prevalence of trypanosome infections in cattle and tsetse flies in the Maasai Steppe, northern Tanzania
}

Mary Simwango ${ }^{1 *}$, Anibariki Ngonyoka ${ }^{2,3}$, Happiness J. Nnko ${ }^{2,3}$, Linda P. Salekwa ${ }^{4}$, Moses Ole-Neselle ${ }^{5}$ Sharadhuli I. Kimera ${ }^{1}$ and Paul S. Gwakisa ${ }^{4}$

\begin{abstract}
Background: African trypanosomosis is a disease of public health and economic importance that poses a major threat to the livelihoods of people living in the Maasai Steppe, where there is a significant interaction between people, livestock and wildlife. The vulnerability of the Maasai people to the disease is enhanced by the interaction of their cattle, which act as vehicles for trypanosomes, and tsetse flies close to wildlife in protected areas. This study was aimed at identification of trypanosome infections circulating in cattle and tsetse flies in order to understand their distribution and prevalence in livestock/wildlife interface areas in the Maasai Steppe.

Methods: A total of 1002 cattle and 886 tsetse flies were sampled from June 2015 to February 2016 in five villages and PCR was conducted to amplify the internal transcribed spacer 1 (ITS1) from trypanosomes. All Trypanosoma brucei-positive samples were further tested for the presence of the serum resistance-associated (SRA) gene found in human-infective trypanosomes using the SRA-LAMP technique.

Results: The overall prevalence of trypanosome infections was $17.2 \%$ in cattle and $3.4 \%$ in tsetse flies. Using a nested PCR, prevalence and abundance of five trypanosome species, Trypanosoma vivax, T. brucei, T. simiae, T. theileri and T. congolense, were determined, which varied with season and location. The highest prevalence of the identified trypanosome species was recorded at the end of wet season with an exception of T. brucei which was high at the beginning of the wet season. No human-infective trypanosomes were detected in both cattle and tsetse fly DNA.

Conclusions: This study confirms that seasonality and location have a significant contribution to the prevalence of trypanosome species in both mammalian and vector hosts. These results are important for designing of community-wide vector and disease control interventions and planning of sustainable regimes for reduction of the burden of trypanosomosis in endemic pastoral areas, such as the Maasai Steppe in northern Tanzania.
\end{abstract}

Keywords: Trypanosomes, Molecular prevalence, Cattle, Tsetse flies, Maasai Steppe, Tanzania

\section{Background}

African trypanosomosis is a disease of public health importance that affects humans and animals. Animal African trypanosomosis (AAT) causes reduced production and animal losses leading to reduced economic growth $[1,2]$ of the Maasai people of northern Tanzania. The Maasai

\footnotetext{
* Correspondence: msimwango@gmail.com

'Department of Veterinary Medicine and Public Health, College of Veterinary Medicine and Biomedical Sciences, Sokoine University of Agriculture (SUA), P.O box 3015, Morogoro, Tanzania

Full list of author information is available at the end of the article
}

pastoralists depend mostly on livestock production for their livelihood, but trypanosomosis is a significant problem in the interface areas due to proximity to wildlife reservoirs. The distribution of African trypanosomosis corresponds to the distribution of tsetse flies transmitting the disease [2, 3]. In Tanzania, Glossina spp. are widely distributed across the country especially in protected areas, game reserves, national parks and wildlife corridors such as the Maasai Steppe. Tsetse density has been shown to be high in the Manyara, Mara and Tanga regions of Tanzania, and Glossina morsitans is the most widely 
distributed tsetse fly species [4]. Subspecies of G. morsitans and G. fuscipes have been reported in western Tanzania while G. pallidipes and G. swynnertoni were reported to be most abundant in northern Tanzania $[4,5]$. These species transmit trypanosomes of importance in Africa including T. congolense, T. suis, T. vivax, T. simiae, T. equipedum, T. evansi, T. godfreyi and T. brucei $[3,6,7]$. These species are widely distributed in animal and human hosts. They cause disease in a wide range of domestic animals including cattle, pigs, camels, goats, sheep, dogs, cats, horses and monkeys $[6,8,9]$.

In East Africa, trypanosomosis has been endemic for a long time following a history of epidemics that occurred in the past [10]. In northern Tanzania, the long standing endemicity of the disease is due to ecological factors and vector biology that support the persistent circulation of trypanosomes $[6,11]$. The ability of tsetse flies to transmit trypanosomes is facilitated by the environment in which the vectors interact with wildlife reservoirs and vulnerable populations in wildlife/livestock/human interface areas. Such an environment provides a suitable setting for transmission and spread of African trypanosomes [12]. The transmission of trypanosomes to susceptible animals and humans is further enhanced by climatic conditions and human activities associated with livestock movement and control regimes in the Maasai Steppe ecosystem [13-17]. Such practices maintain trypanosome circulation in vectors and livestock by creating carriers, which may not be detected in a population due to lack of clinical symptoms. However, molecular diagnostic techniques have made it possible to detect and identify infections even prior to the manifestation of the disease $[6,18]$. The polymerase chain reaction has successfully been used for detection and characterization of infectious agents [19]. Several oligonucleotide primers have been developed to amplify trypanosome genes, some of which are generic or species-specific. The sensitivity of these primers has been reported previously [20-23].

Due to insufficient knowledge on the current status of trypanosomosis, there are no sustainable means or uniform vector control regimes suitable for interface areas, and this situation increases the vulnerability of humans and their livestock to trypanosomosis. Therefore, understanding of current infection status is key to providing the required knowledge for controlling African trypanosomoses appropriately. The aim of this study was to quantify trypanosome infections circulating in cattle and tsetse flies and understand their distribution and prevalence in livestock/wildlife interface areas of the Maasai Steppe, Tanzania.

\section{Methods}

\section{Study area}

The study was conducted in the Maasai Steppe of northern Tanzania, made up of Simanjiro plains, Tarangire
National park and Lake Manyara National park [24]. It lies between $3^{\circ} 52^{\prime}$ and $4^{\circ} 24^{\prime} \mathrm{S}$ and $36^{\circ} 05^{\prime}$ and $36^{\circ} 39^{\prime} \mathrm{E}$. The area has two rainfall seasons of spatial and temporal variation, comprising of short rains between October and December and long rains from February to May. The average temperature in the area is between $18{ }^{\circ} \mathrm{C}$ and $30{ }^{\circ} \mathrm{C}$. The Maasai Steppe is made up of natural semi-arid ecosystem providing a home for a variety of animal species, vegetation, conducive temperature variations and rainfall, all of which support a natural habitat for vectors and various parasitic organisms [25]. Livestock and crop production are the main sources of livelihood in the Maasai Steppe with cattle production being the major activity [26]. Due to its proximity to the protected areas, the study area has the high interaction of wild, domestic animals and humans which increases circulation of trypanosomes through bites from tsetse flies, making trypanosomosis endemic in the area.

\section{Study design}

A repeated cross-sectional, observational study design was used in which three samplings were conducted. A multistage cluster sampling technique was used to select cattle whereby Lake Manyara and Tarangire National parks were used as land marks for the study. The sampling allowed a comparison of the magnitude of trypanosome infections between the end of wet (June 2015), dry (August 2015) and the beginning of wet (February 2016) seasons. Blood samples were collected from 1002 cattle in five villages (Fig. 1): Emboreet $(n=340)$, Loiborsiret $(n=200)$, Kimotorok $(n=200)$, Loiborsoit $(n=60)$ and Ortukai $(n=202)$. The five villages were selected based on their proximity to Tarangire National park, in the same areas where tsetse flies were captured. In each village, $50 \%$ of sub-villages were selected at random, and $50 \%$ of all bomas in each sub-village were selected systematically. A boma was taken as a sampling unit in which animals were selected at random. A boma is a traditional Maasai homestead, usually consisting of a number of huts surrounding an enclosure for livestock, especially cattle. The average number of cattle sampled per boma was seven, and a total of 94 bomas were selected. Sample size calculation was based on the assumption of a 95\% confidence level, 27.5\% [11] expected trypanosome parasite prevalence, 0.05 tolerable error and a design effect of 1.2 for cluster sampling.

\section{Blood sample collection and trapping of tsetse flies}

Blood samples were taken from each animal by jugular venipuncture using $10 \mathrm{ml}$ vacutainer tubes (Becton Dickinson Vacutainer Systems, Plymouth, UK) containing ethylenediaminetetraaceticacid (EDTA) anticoagulant. Blood samples were then kept in cool boxes on ice for $2-5 \mathrm{~h}$ before refrigeration. The blood samples were 


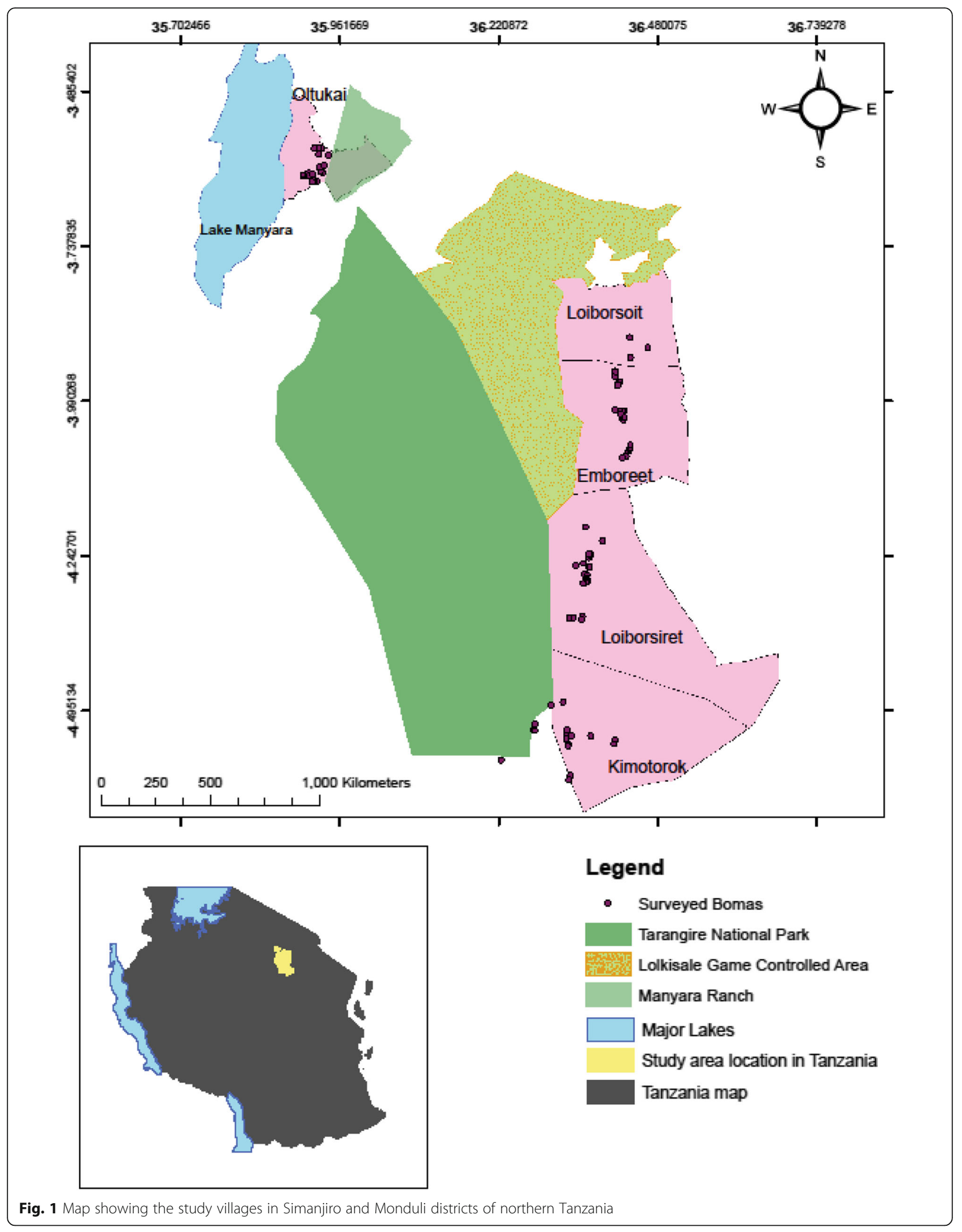


further stored in a freezer at $-20{ }^{\circ} \mathrm{C}$ until the day of DNA extraction.

A total of 886 tsetse flies were collected in June 2015 using Epsilon traps odour-baited with an attractant made from acetone, phenols and octanol. Traps were set at 27 sites in the study villages for a month, where they were checked and emptied every six days. Each trapped fly was kept in a separate Eppendorf tube with 70\% ethanol at room temperature until DNA extraction.

\section{DNA extraction}

DNA was extracted from cattle blood as described in the protocol by Quick-gDNA blood mini prep kit (Zymo Research, Irvine, CA, USA). Ground tsetse flies were individually put in a ZR Bashing Bead ${ }^{\mathrm{m}}$ Lysis Tube, and DNA was extracted using the protocol by ZR Tissue and Insect DNA Mini Prep, (Zymo Research). Fifty microlitres of DNA was eluted in Eppendorf tubes and stored at $-20{ }^{\circ} \mathrm{C}$ until further analysis.

\section{PCR identification of trypanosome species}

A nested PCR was employed using two sets of primers comprising of outer forward (5'-GAT TAC GTC CCT GCC ATT TG-3') and reverse (5'-TTG TTC GCT ATC GGT CTT CC-3') primers, and inner forward (5'-GGA AGC AAA AGT CGT AAC AAG G-3') and reverse (5'TGT TTT CTT TTC CTC CGC TG-3') primers [20, 22]. The nested PCR ( $\mathrm{nPCR}$ ) reaction was conducted in a $12.5 \mu \mathrm{l}$ reaction comprising of $6.25 \mu \mathrm{l}$ mastermix (Quick-Load Taq 2× Master Mix, New England BioLabs Inc., Ipswich, MA, USA), $2.5 \mu$ l DNA template, $3.25 \mu \mathrm{l}$ nuclease free water and $0.2 \mu \mathrm{M}$ of each first round primer. The second round amplification was performed using primers at the same concentration as the first round, $1 \mu \mathrm{l}$ of the PCR products from the first round was used as a template and $4.75 \mu \mathrm{l}$ of nuclease free water. Amplification conditions involved an initial denaturation step at $95{ }^{\circ} \mathrm{C}$ for $7 \mathrm{~min}$ followed by 35 cycles of denaturation at $94{ }^{\circ} \mathrm{C}$ for one min, an annealing step at $55{ }^{\circ} \mathrm{C}$ for one min, then extension step of $72{ }^{\circ} \mathrm{C}$ for two min and a final extension at $72{ }^{\circ} \mathrm{C}$ for $10 \mathrm{~min}$. The PCR products were loaded on 1.5\% agarose gel stained with GRGreen Nucleic Acid Stain (Excellgen, Inc., Rockville, MA, USA) and visualized on a Gel DocTM (Bio Rad, Hercules, CA, USA).

Additionally, a single step PCR for the identification of ITS 1 gene was used to compare the prevalence of trypanosome infections in cattle and tsetse flies. Briefly, primers with the following sequences were used: $\mathrm{F}$ : $5^{\prime}$ CCG GAA GTT CAC CGA TAT TG-3' and R: 5' -TTG CTG CGT TCT TCA ACG AA-3' [27]. The reaction was performed in a $25 \mu \mathrm{l}$ reaction volume containing $12.5 \mu \mathrm{l}$ of mastermix (Quick-Load Taq 2× Master Mix, New England BioLabs Inc., Ipswich, MA, USA) containing DreamTaq DNA polymerase supplied in $2 \times$ DreamTaq buffer, $0.4 \mathrm{mM}$ of each of the dATP, dCTP, dGTP and dTTP, and $4 \mathrm{mM} \mathrm{MgCl}_{2}, 0.2 \mu \mathrm{M}$ of each of the forward and reverse primers, $6.3 \mu \mathrm{l}$ nuclease free water and $5 \mu \mathrm{l}$ DNA template. The reaction was conducted in a thermocycler (ProFlex PCR system, Applied Biosystems, Foster City, CA, USA) with an initial denaturation step of $94{ }^{\circ} \mathrm{C}$ for $3 \mathrm{~min}$, followed by 30 cycles of $94{ }^{\circ} \mathrm{C}$ for $30 \mathrm{~s}, 55{ }^{\circ} \mathrm{C}$ for $30 \mathrm{~s}, 72{ }^{\circ} \mathrm{C}$ for $30 \mathrm{~s}$ and a final extension step at $72{ }^{\circ} \mathrm{C}$ for $10 \mathrm{~min}$ [28]. Expected fragment size for individual trypanosome species is shown in Table 1.

\section{SRA-LAMP for detection of human-infective trypanosomes}

All T. brucei positive DNA from cattle and tsetse flies were subjected to SRA-LAMP technique to detect human-infective trypanosomes (T. b. rhodesiense) [29]. The technique was performed using the primer sequences shown in Table 2. SRA-LAMP was conducted in $25 \mu$ reaction volume containing $2.5 \mu \mathrm{l}$ of $1 \times$ Thermopol buffer, $5 \mu \mathrm{l}$ of $0.8 \mathrm{M}$ betaine, $1 \mu \mathrm{l}$ of $200 \mu \mathrm{M}$ dNTPs, $1 \mu \mathrm{l}$ of $0.2 \mu \mathrm{M}$ F3 and B3 primers, $1 \mu \mathrm{l}$ of $2 \mu \mathrm{M}$ FIP and BIP primers, $1 \mu \mathrm{l}$ of $0.8 \mu \mathrm{M}$ loop primers $\mathrm{LB}$ and LF, $1 \mu \mathrm{l}$ of $8 \mathrm{U}$ Bst DNA polymerase, $2 \mu \mathrm{l}$ of DNA template and $7.5 \mu \mathrm{l}$ of nuclease free water. Reaction conditions for the SRA-LAMP were set at $62{ }^{\circ} \mathrm{C}$ for $1 \mathrm{~h}$ in a GeneAmp ${ }^{\oplus}$ PCR system 9700 (Applied Biosystems, Foster City, CA, USA). The reaction was terminated by increasing the temperature to $80{ }^{\circ} \mathrm{C}$ for $5 \mathrm{~min}$. The SRALAMP products were visualised through colour change after addition of $2 \mu \mathrm{l} \mathrm{SYBR}$ Green I. An orange colour indicated negative results while the colour change to green signified positive results. The SRA-LAMP products were confirmed by gel electrophoresis using $1.5 \%$ agarose gel prepared in $1 \times \mathrm{TBE}$ and stained with $1 \mu \mathrm{l}$ of $10 \mathrm{mg} / \mathrm{ml}$ ethidium bromide. The products were separated at $120 \mathrm{~V}$ for $30 \mathrm{~min}$ and visualised using Ultra violet trans-illuminator (UVDoc ${ }^{\mathrm{TM}}$ Merton, UK).

Table 1 Expected band sizes of trypanosome species amplified by two methods

\begin{tabular}{lll}
\hline Trypanosome species & ITS1 PCR (bp) & Nested ITS PCR (bp) \\
\hline T. congolense forest & 710 & 1513 \\
T. congolense savannah & 700 & 1413 \\
T. congolense kilifi & 620 & 1422 \\
T. brucei & 480 & $1207-1224$ \\
T. simiae & 400 & 850 \\
T. vivax & 250 & 611 \\
T. theileri & & 988 \\
\hline
\end{tabular}


Table 2 SRA-LAMP primer sequences

\begin{tabular}{lll}
\hline Primer & Primer type & Primer sequence (5'-3') \\
\hline SRA-F3 & F3 & GCGGAAGCAAGAATGACC \\
SRA-B3 & B3 & TCTTACCTTGTACGCCTG \\
SRA-FIP & FIP & GGACTGCGTTGAGTACGCATCCGCAAGCACAGACCACAGC \\
SRA-BIP & BIP & CGCTCTTACAAGTCTTGCGCCTTCTGAGATGTGCCCACTG \\
SRA-LF & LF & CGCGGCATAAAGCGCTGAG \\
SRA-LB & LB & GCAGCGACCAACGGAGCC \\
\hline
\end{tabular}

\section{Data analysis}

The prevalence of infections was estimated using frequency and contingency tables in Excel and Epi Info ${ }^{\mathrm{Tm}}$ version 7.0 (CDC, Atlanta, GA, USA) statistical software. Comparative location and seasonal prevalence were estimated using contingency tables, and logistic regression where the Chi-square expected and $P$-values were obtained. The chi-square values were obtained by a test of independence and homogeneity of proportions between dependent (outcome) and independent (exposure) variables using Pearson uncorrected test. Chi-square was used when all expected values were greater than five while Mid$P$ values for two-way tables were obtained when at least one expected value (row total*column total/grand total) was less than five. All $P$-values for tables with zero values were obtained with the assumption that 0.5 was added. The $P$-values of the results were analysed (using $P=0.05$ as a cut-off value) at $95 \%$ confidence intervals to indicate the level of uncertainty around the obtained values.

\section{Results}

Prevalence of trypanosome infections in cattle

The overall prevalence of trypanosome infections in cattle detected using the nested PCR assay (Fig. 2) was 17.2\% (172/1002; 95\% CI: 14.91-19.68) (Table 3).
Prevalence of trypanosome infections varied between the five different villages significantly $(P=0.0003)$. Thus, the highest prevalence was found in Loibor-soit-A village (35.0\%) followed by Kimotorok (20.5\%), whereas lowest prevalence $(12.1 \%)$ was observed in Emboreet village. The differences in prevalence between Kimotorok and Emboreet $(P=0.009)$ as well as Loibor-soit-A and Emboreet $(P<0.0001)$ were significant. No statistical significance was however observed when the prevalence of trypanosome infections was compared between different age or sex groups, although a strong association between prevalence and age of the animal was documented $\left(\chi^{2}=32.91, P=0.0631\right)$. Thus, highest prevalence $(40.0 \%)$ was observed in cattle aged older than 10 years, whereas lowest prevalence (16.3\%) was detected in cattle aged between 2 and 6 years and those younger than 2 years. Although infection prevalence was higher in female cattle (17.5\%) than in males $(16.4 \%)$, this difference was not statistically significant (Table 3 ).

\section{Abundance of single and mixed trypanosome infections in cattle}

A total of 239 trypanosome infections were scored in the 172 positive cattle. While most cattle were infected with single trypanosome species (115/172 cattle; 66.9\%),

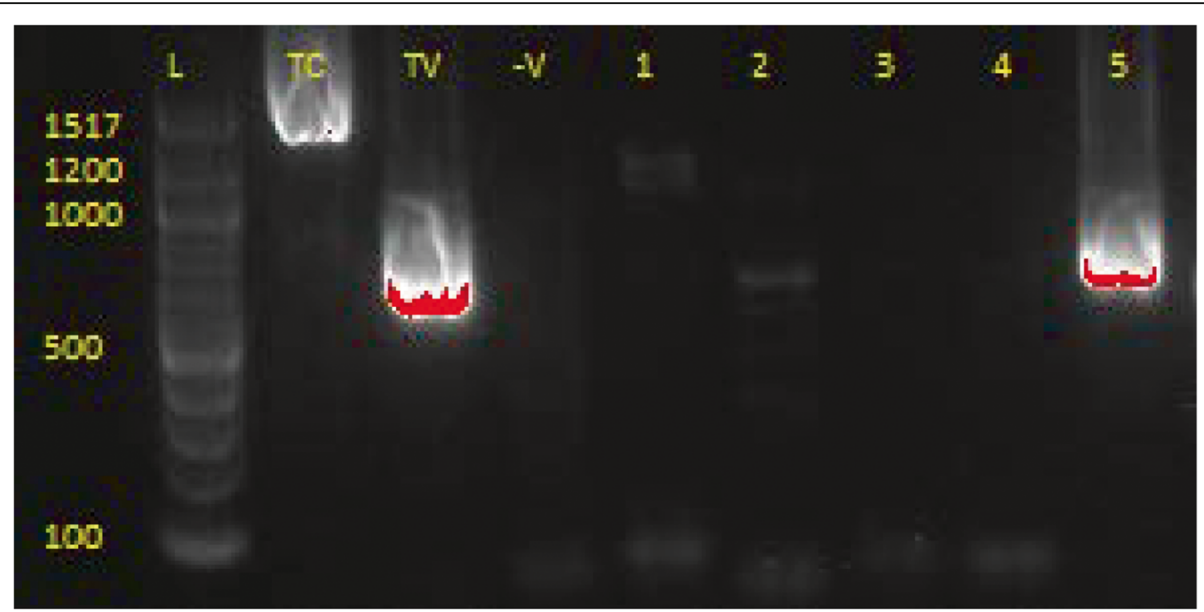

Fig. 2 A gel picture of trypanosomes amplified using nPCR. Lane L: a 100 base pair (bp) DNA ladder; Lanes TC and TV: positive controls for T. congolense and T. vivax, respectively; Lane -V: negative control; Lanes 1-5: cattle DNA samples. Lane 1 shows a weak T. brucei-positive sample, Lanes 2 and 5 are T. vivax-positive samples and Lanes 3 and 4 are negative samples 
Table 3 Prevalence of trypanosome infections in the study population of cattle by village, age and sex

\begin{tabular}{|c|c|c|c|c|c|c|}
\hline Category & Sub-category & No. of cattle screened & No. of trypanosome infections & Prevalence (\%) & $x^{2}$ & $P$-value \\
\hline \multirow[t]{6}{*}{ Village } & Emboreet & 340 & 41 & 12.1 & 21.42 & 0.0003 \\
\hline & Kimotorok & 200 & 41 & 20.5 & & \\
\hline & Loiborsiret & 200 & 36 & 18.0 & & \\
\hline & Loibor-soit-A & 60 & 21 & 35.0 & & \\
\hline & Ortukai & 202 & 33 & 16.3 & & \\
\hline & Total & 1002 & 172 & 17.2 & & \\
\hline \multirow[t]{5}{*}{ Age (years) } & $<2$ & 301 & 51 & 16.9 & 32.91 & 0.0631 \\
\hline & $2-6$ & 484 & 79 & 16.3 & & \\
\hline & $6-10$ & 212 & 40 & 18.9 & & \\
\hline & $>10$ & 5 & 2 & 40.0 & & \\
\hline & Total & 1002 & 172 & 17.2 & & \\
\hline \multirow[t]{3}{*}{ Sex } & Female & 716 & 125 & 17.5 & 0.15 & 0.6977 \\
\hline & Male & 286 & 47 & 16.4 & & \\
\hline & Total & 1002 & 172 & 17.2 & & \\
\hline
\end{tabular}

$27.9 \%(48 / 172)$ of the trypanosome-infected cattle carried multiple infections with two trypanosome species, $4.7 \%(8 / 172)$ carried three trypanosomes, and one animal $(1 / 172 ; 0.6 \%)$ was infected with four trypanosome species. The most frequent multiple infections were $T$. vivax/T. simiae occurring in $12.8 \%(22 / 172)$ of infected cattle followed by $T$. brucei/T. vivax (5.2\%; 9/172). Trypanosoma vivax was the most abundant species (100/ 239), followed by T. brucei (50/239), T. simiae (47/239), T. theileri (24/239) and T. congolense (18/239). Trypanosoma vivax was the most abundant in all villages except in Loibor-soit-A, where T. brucei was most abundant. The distribution of these species by village is as shown in Fig. 3. The highest number of trypanosome infections was documented in Kimotorok village (68/239), while least infections were found in Loibor-soit-A (26/239).

\section{Seasonal distribution of trypanosome infections}

The overall prevalence of trypanosome infections in cattle was higher at the end of wet season (18.7\%) than at the beginning of the wet season $(16.5 \%)$ or in the dry season (16.0\%). The seasonal variation was not statistically significant neither when the overall cattle population was considered nor when the cattle were split by village (Table 4). However, a significant seasonal variation of prevalence of individual trypanosome species was obtained when $T$. brucei and $T$. theileri were analysed $(P=0.025)$ (Table 5).

Prevalence of trypanosomes in cattle and tsetse flies

Trypanosome infections were concurrently studied in cattle and tsetse flies in order to determine the variation of prevalence spatially. Table 6 shows the spatial variation

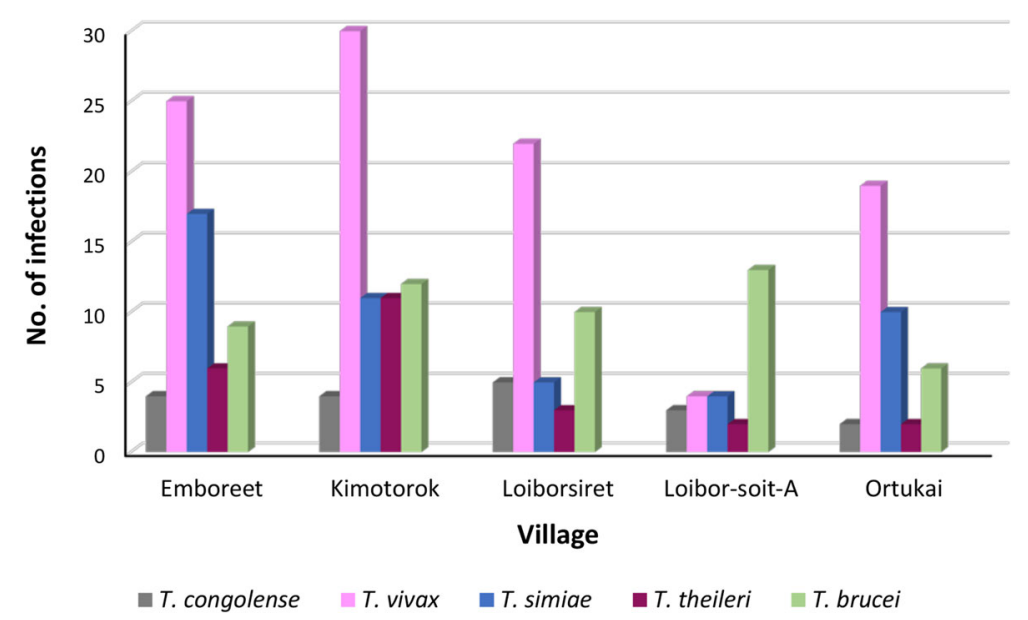

Fig. 3 Spatial distribution of trypanosome species in the Masaai Steppe 
in the two hosts and Fig. 4 shows the bands obtained using ITS 1 single PCR.

The overall prevalence of trypanosomes using a single step PCR for the ITS 1 gene was significantly higher in cattle $(13.4 \%)$ than in tsetse flies $(3.4 \%)(P<0.0001)$ (Table 5). However, when prevalence in cattle and tsetse flies was examined in individual villages, a different trend was shown in different villages. For example, in Emboreet village the prevalence of trypanosomes was high in tsetse flies $(13.9 \%)$ but slightly lower in cattle (13.0\%) whereas in Kimotorok village, a 0\% prevalence was shown in tsetse flies but $21.0 \%$ prevalence in cattle. Trypanosoma vivax was the most prevalent infection in tsetse flies $(21 / 30 ; 70.0 \%)$ compared to that of $T$. brucei (6/30; 20.0\%) and T. congolense $(3 / 30 ; 10.0 \%)$. None of the tsetse flies collected during this period had mixed trypanosome infections, and none of the T. brucei positive DNA was positive for human-infective trypanosome species (T. b. rhodesiense).

\section{Discussion}

This study established a $17.2 \%$ prevalence of trypanosome infections in cattle in the selected villages of the Maasai Steppe. The prevalence reflects trypanosome infections in cattle regardless of their clinical status at the time of sampling. The prevalence level further indicates the potential risk for pastoral cattle to suffer from trypanosomosis and spread the infections to other animals through tsetse fly bites. This prevalence is higher than the $5 \%$ reported by others [30] using parasitological (microscopy) methods to detect active disease in the same area. One of the reasons behind the difference in the prevalence is the sensitivity of PCR compared to microscopy in the detection of trypanosomes. Further, PCR detects both clinical and subclinical infections which include pathogenic and non-pathogenic trypanosomes. Only cattle infected with pathogenic trypanosomes would show clinical signs depending on the virulence of the infecting species involved. For example, cattle infected with $T$. congolense are more likely to show clinical signs than cattle infected with $T$. theileri $[6,31,32]$. The $17.2 \%$ prevalence of trypanosome infections reported in this study also reflects the high trypanosome transmission intensity in livestock-wildlife interface areas, as may be expected in the Maasai Steppe ecosystem, Several other studies have also reported a similar prevalence using PCR methods [21, 33, 34].

The present study compared the prevalence of trypanosome infections in different age groups of cattle. Higher prevalence of trypanosome infections was shown in cattle that were older than 2 years compared to younger ones, although the difference between age groups was not significant. Interestingly, a high strength of association was shown between age and infection prevalence $\left(\chi^{2}=32.9\right)$. This finding was expected since older cattle grazed in tsetse fly infested areas whereas younger animals grazed close to homesteads, hence their lower exposure to tsetse bites. Our study has shown a significant variation of prevalence of trypanosome infections between villages. The variation may be ascribed to differences in community practices for vector control between villages as well as livestock movement often towards protected areas with high abundance of wildlife. Seasonal livestock movement from one village to another in search of pasture and water is a common phenomenon in the Maasai Steppe, and such movements are expected to influence the prevalence of trypanosome infections. Furthermore, the movement of cattle herds increases their interaction with tsetse flies and wildlife through shared grazing fields and hence the potential for disease transmission between wild and domestic hosts [5]. Thus vector control is essential to cattle in these areas especially in villages like Loiborsoit-A where the prevalence of trypanosomes was high, and Kimotorok and Loiborsiret which are closest to Tarangire National park. The most common vector control method in the Maasai Steppe is the use of acaricide sprayers, which is not very cost-effective and is labour intensive. The ideal method would be to use dip tanks most of which are not functional due to structural damage and water shortage to refill the tanks. However, regular dipping of cattle before and after seasonal livestock movements to highly infested areas is essential [35, 36], what will complement already existing communitylevel vector control strategies and hence reduce trypanosome infections.

We have shown that the overall prevalence of trypanosome infections was higher at the end of wet season (18.7\%) than during the dry and beginning of wet seasons. However, the seasonal variation was not significant. The non-significant overall variation of trypanosome

Table 4 Seasonal variation of trypanosome infections in cattle

\begin{tabular}{|c|c|c|c|c|}
\hline Season & No. of cattle & Prevalence of infection, $n$ (\%) & $x^{2}$ & $P$-value \\
\hline Early wet & 200 & $33(16.5)$ & 1.0731 & 0.5848 \\
\hline End of wet & 402 & $75(18.7)$ & & \\
\hline Dry & 400 & $64(16.0)$ & & \\
\hline Total & 1002 & $172(17.2)$ & & \\
\hline
\end{tabular}


Table 5 Distribution of trypanosome infections across seasons

\begin{tabular}{|c|c|c|c|c|c|c|}
\hline \multirow[t]{2}{*}{ Species } & \multirow{2}{*}{$\begin{array}{l}\text { Total no. } \\
\text { of } \\
\text { infections }\end{array}$} & \multicolumn{3}{|l|}{ No. of infections (\%) } & \multirow[t]{2}{*}{$x^{2}$} & \multirow[t]{2}{*}{$P$-value } \\
\hline & & End of wet season & Dry season & Beginning of wet season & & \\
\hline T. vivax & 100 & $11.9(48)$ & $10(40)$ & $6(12)$ & 5.25 & 0.072 \\
\hline T. congolense & 18 & $2.49(10)$ & $1(4)$ & $2(4)$ & 2.58 & 0.275 \\
\hline T. brucei & 50 & $5.47(22)$ & $3(12)$ & $8(16)$ & 7.36 & 0.025 \\
\hline T. simiae & 47 & $6.22(25)$ & $4(16)$ & $3(6)$ & 3.81 & 0.149 \\
\hline T. theileri & 24 & $3.98(16)$ & $1.5(6)$ & $1(2)$ & 7.36 & 0.025 \\
\hline
\end{tabular}

infections could be due to chronicity of the parasites what can potentially lead to persistent trypanosome infections across seasons [37]. However, when individual trypanosome species were considered, significant seasonal variation was shown between $T$. brucei (whose prevalence was higher at the beginning of the wet season) and T. theileri. The variation of individual trypanosome species could also be due to biology and epidemiology of tsetse flies transmitting individual parasites. For example, Glossina morsitans is a good vector for T. congolense [38] while G. pallidipes, G. morsitans and G. swynnertoni are efficient vectors for T. brucei $[5,39]$. Trypanosoma theileri is not dependent on the tsetse fly distribution but that of Tabanid flies [8]. In the Maasai Steppe, cattle come into close contact with the vectors either during normal grazing or movement due to seasonal changes in pasture availability. Another reason explaining the seasonal variation of the different trypanosome species is the potential mechanical transmission component of $T$. congolense and $T$. vivax, whose transmission is also dependant on tabanid and Stomoxys flies [40].

This study identified both pathogenic and nonpathogenic trypanosomes in cattle. The most prevalent trypanosome species was $T$. vivax which comprised $41.8 \%(100 / 239)$ of the overall infections. The abundance of $T$. vivax is consistent with its transmission pattern giving it more chances of infection in cattle. The high abundance of $T$. vivax and $T$. brucei could explain the persistent subclinical infections exhibited by cattle in the Maasai Steppe [41], compared to less prevalent infections by pathogenic $T$. congolense as suggested by our study.
We report that $33.1 \%$ (57/172) of trypanosome positive cattle harboured mixed infections of two up to four trypanosome species. Mixed infections in mammalian hosts increase utilisation for nutrients and immune components due to competition for space and resources by trypanosomes leading to clinical implications on the host. This finding suggests that cattle in such endemic areas like the Maasai Steppe go through rounds of infection and re-infection with different trypanosome species, hence the persistence and chronicity of infections. Further, local cattle breeds may have adapted to live with low doses of trypanosomes in their blood without showing any signs of infection. However, this does not exempt them from getting multiple trypanosome infections. Another reason behind the occurrence of mixed trypanosome infections is the ability of tsetse flies to carry more than one species of trypanosomes. This is attributed to the different developmental predilection sites of trypanosome species. For example, $T$. congolense develops in the midgut while $T$. vivax develops entirely in the proboscis. This means that one tsetse fly can transmit more than one trypanosome species [42]. In the present study, we found $T$. vivax/T. simiae combination as the most frequent mixed infection which appeared in $26.4 \%$ of the positive cattle in all five villages. Trypanosoma simiae is considered not infective for cattle and therefore not pathogenic in cattle but very pathogenic to pigs. The presence of this species in cattle is not a common finding but has been reported before [32, 43]. The impact of the presence of this trypanosome species on the epidemiology of the disease is unclear so far although it suggests that pigs could be at risk of infection if exposed to both $T$. simiae-infected cattle and tsetse flies. However,

Table 6 Trypanosome prevalence in cattle and tsetse flies

\begin{tabular}{|c|c|c|c|c|c|}
\hline \multirow[t]{2}{*}{ Village } & \multicolumn{2}{|l|}{ Cattle } & \multicolumn{2}{|l|}{ Tsetse flies } & \multirow[t]{2}{*}{$P$-value } \\
\hline & No. screened & No. of infections (\%) & No. screened & No. of infections (\%) & \\
\hline Emboreet & 100 & $13(13.0)$ & 72 & $10(13.9)$ & 0.8658 \\
\hline Kimotorok & 100 & $21(21.0)$ & 9 & $0(0)$ & 0.1340 \\
\hline Loiborsiret & 100 & $10(10.0)$ & 750 & $20(2.7)$ & 0.0016 \\
\hline Ortukai & 102 & $10(9.8)$ & 55 & $0(0)$ & 0.0114 \\
\hline Total & 402 & $54(13.4)$ & 886 & $30(3.4)$ & $<0.0001$ \\
\hline
\end{tabular}




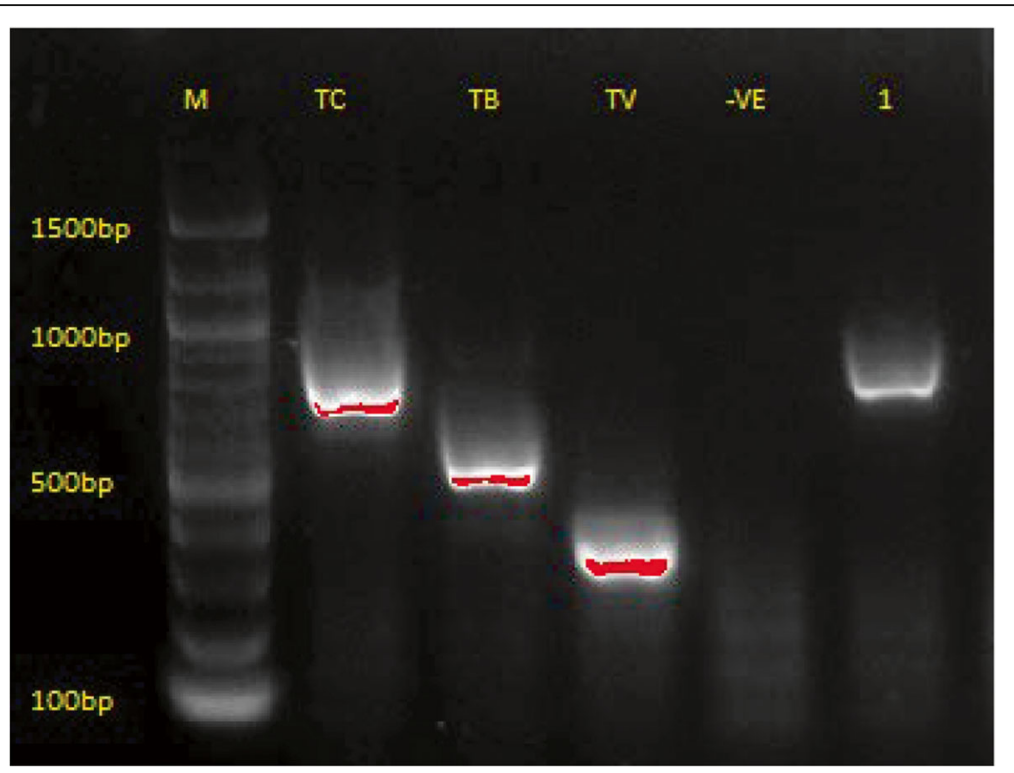

Fig. 4 A gel of ITS1 single PCR. Lane M: DNA marker; Lanes TC, TB and TV: positive controls for T. congolense, T. brucei and T. vivax, respectively; Lane -VE: negative control; Lane 1: positive sample of T. congolense (700 bp)

most Maasai people do not rare pigs and as such this risk may not be anticipated. Mixed infections by pathogenic strains would lead to the manifestation of clinical signs in an infected host while infection by non-pathogenic species would result in chronicity of sub-clinical infections [44]. The mixed trypanosome infections in cattle reported here are comparable to those found in tsetse flies [45], where T. vivax/T. simiae/T. brucei was most abundant.

As expected, the overall prevalence of trypanosome infections was lower in tsetse flies than in cattle mostly because one tsetse fly can transmit trypanosomes to more than one animal. This finding could also be due to the fact that majority of trapped tsetse flies are comprised of unfed flies [46, 47], which normally have a lower chance of carrying trypanosome infections. The epsilon traps used in this study are known to be selectively specific to savannah tsetse flies (G. pallidipes and G. morsitans) and hence may leave out other tsetse fly species responsible for transmitting some species of trypanosomes [48-50]. Nevertheless, the prevalence of trypanosome infections in tsetse flies found in this study was higher than the previously reported values $[5,51]$ in the same study area. Higher infection prevalence in cattle, however, is due to the fact that cattle undergo multiple tsetse fly bites and each biting tsetse fly can transmit infections to several hosts giving cattle a higher prevalence of infections. On the other hand, the prevalence of trypanosome infections in cattle and tsetse flies reported for individual villages shows an inconsistent relationship, suggesting that high infection rates in flies do not necessarily mean high prevalence of trypanosomes in cattle (Table 6). This finding is most likely associated with human activities such as livestock movements, vector and disease control practices, which in the Maasai Steppe can be unpredictable. These findings entail that infections vary with time of the year (season) and location. This study also established a zero prevalence of mixed trypanosome infections in tsetse flies as opposed to the results reported by others $[5,45]$. This finding could have been momentary considering that the study was conducted within a period of one month (June). An intensive or temporal study of mixed infections in tsetse flies could yield more information. However, the absence of mixed infections in this study could also be attributed to self- regulation and inhibition that takes place in the vectors [52]. The variation of trypanosome infections between cattle and tsetse flies could guide the Maasai pastoral communities living in tsetse fly infested areas when to control the disease strategically. The current study also showed no human-infective trypanosomes in both cattle and tsetse flies. These results are comparable to other studies conducted in the same area by others [ 5 , $41,51]$ who found no human-infective trypanosomes in northern Tanzania. Other studies have reported the presence of human-infective trypanosome in areas close to our study area [11]. The absence of circulating human-infective trypanosomes in the study area does not, however, call for relaxed control and surveillance, since the presence of reservoir hosts signifies an existing risk of emergence of the human-infective trypanosomes. Thus our study emphasizes the importance of enhanced control efforts by integrating the use of tsetse fly traps, chemotherapeutic and chemoprophylactic drugs that control the prevalent trypanosome species (including $T$. 
brucei), on livestock to maximize vector control in areas where tsetse flies are most abundant.

\section{Limitations of the study}

As much as ITS 1 primers produced baseline results for trypanosome infections, they amplified only 3 species of trypanosomes (T. congolense, T. brucei and T. vivax) and rarely showed mixed infections under our laboratory conditions. This could be one of the reasons for zero prevalence of mixed infections in tsetse flies. On the other hand, ITS nested primers yielded higher fragment resolution. However, the nested PCR also produced fragments which are not among the listed sizes for trypanosome species. Such fragments may represent novel trypanosome species, and further studies on these fragments are in progress to clarify the identity of these putative bands.

\section{Conclusions}

In summary, this study has established the seasonal and spatial prevalence of trypanosome infections in cattle and tsetse flies in villages in Simanjiro and Monduli districts of the Maasai Steppe. Age, sex and season did not significantly influence the prevalence of trypanosome infections. However, the location of the villages in relation to proximity to wildlife showed positive influence on the prevalence of trypanosome infections, with a high number of cattle carrying mixed trypanosome infections. This study has evidenced the circulation of five trypanosome species and factors that influence their occurrence. Factors such as geographical distribution of all trypanosome species and tsetse flies can be used as a guide to improved control measures. The knowledge and awareness of trypanosome infection distribution will enhance concrete human based control measures by the Maasai communities. These findings can also help strengthen trypanosomosis control measures at regional and national levels through implementation of active surveillance systems.

\section{Acknowledgements}

We acknowledge the Maasai communities for their willingness to participate in the study, Professor Richard Silayo of the Sokoine University of Agriculture, Dr Imna Malele of Vectors and Vector borne Disease Research Institute, Tanga and Dr Francis Mwanza are acknowledged for their contributions to this study.

\section{Funding}

This research received financial support from the project "Predicting vulnerability and improving the resilience of the Maasai communities to vector borne infections: An Eco-health approach in Maasai Steppe ecosystem", based at the Nelson Mandela African Institution of Science and Technology (NM-AIST) in Arusha, Tanzania. The project was funded by UNICEF/UNDP/World BankWHO Special Programme for Research and Training in Tropical Diseases (TDR) and the Canadian International Development Research Centre (IDRC) through the research programme Population Health Vulnerabilities to Vector Borne Diseases: Increasing resilience under climate change conditions in Africa. Additional support was obtained from Intra-African Caribbean and Pacific (ACP) Academic
Mobility Scheme through the EOHMob project (Grant award 2012-3166) of the EACEA coordinated by Sokoine University of Agriculture.

\begin{abstract}
Availability of data and materials
The datasets generated and/or analysed during the current study are not publicly available because they are to be used for subsequent publications but are available from the corresponding author on reasonable request.
\end{abstract}

\section{Ethics approval and consent to participate}

Ethical clearance (NIMR/HQ/R.8c/Nol.11/428) for the study was obtained from National Institute for Medical Research in Tanzania, and verbal consent was obtained from livestock owners during data collection.

\section{Authors' contributions}

MS and PSG designed the study and wrote the draft and final version of the manuscript. MS and LPS collected data and conducted laboratory analysis.

PSG and SIK supervised MS throughout the research and manuscript writing. AN and HN collected tsetse flies and MN coordinated field activities. All authors read and approved the final manuscript.

\section{Consent for publication}

Not applicable.

\section{Competing interests}

The authors declare that they have no competing interests.

\section{Publisher's Note}

Springer Nature remains neutral with regard to jurisdictional claims in published maps and institutional affiliations.

\section{Author details}

${ }^{1}$ Department of Veterinary Medicine and Public Health, College of Veterinary Medicine and Biomedical Sciences, Sokoine University of Agriculture (SUA), P.O box 3015, Morogoro, Tanzania. ${ }^{2}$ Nelson Mandela African Institution of Science and Technology, School of Life Sciences and Bioengineering, P. O. Box 447, Arusha, Tanzania. ${ }^{3}$ Department of Geography and Environmental Studies, University of Dodoma, P. O. Box 395, Dodoma, Tanzania. ${ }^{4}$ Genome Sciences Centre, Department of Microbiology, Parasitology and Biotechnology, College of Veterinary Medicine and Biomedical Sciences, Sokoine University of Agriculture, Morogoro, Tanzania. ${ }^{5}$ FAO Emergency Centre for Transboundary Animal Disease (ECTAD), P.O Box 2, Dar es Salaam, Tanzania.

Received: 2 February 2017 Accepted: 28 September 2017

Published online: 23 October 2017

\section{References}

1. Chanie M, Adula D, Bogale B. Socio-economic assessment of the impacts of trypanosomosis on cattle in Girja district, southern Oromia region, southern Ethiopia. Acta Parasitol. 2013;4(3):80-5.

2. Firesbhat A, Desalegn C. Epidemiology and impacts of trypanosomosis in cattle. Eur J Appl Sci. 2015;7(5):220-5.

3. Steverding D. The history of African trypanosomosis. Parasit Vectors. 2008;1:3.

4. Malele I, Nyingilili $H$, Msangi A. Factors defining the distribution limit of tsetse infestation and the implication for livestock sector in Tanzania. Afr J Agric Res. 2011;6:2341-7.

5. Salekwa LP, Nnko HJ, Ngonyoka A, Estes AB, Agaba M, Gwakisa PS. Relative abundance of tsetse fly species and their infection rates in Simanjiro, northern Tanzania. Livestock Res Rural Dev. 2014;26:213.

6. CFSPH: African Animal Trypanosomosis. 2009. http://www.cfsph.iastate.edu/ Factsheets/pdfs/trypanosomiasis_african.pdf. Accessed 21 May 2016.

7. OIE: Trypanosomosis tsetse-transmitted. 2013. http://www.oie.int/fileadmin/ Home/eng/Animal_Health_in_the_World/docs/pdf/Disease_cards/ TRYPANO_TSETSE.pdf. Accessed 12 Apr 2016.

8. Pollock JN. Training Manual for Tsetse Control Personnel. In: Tsetse biology, systematics and distribution, techniques. Food and Agricultural Organization;1992. http://www.fao.org/docrep/009/p5178e/P5178E07. htm\#ch6. Accessed 5 Apr 2016.

9. Bengis RG, Kock RA, Fischer J. Infectious animal diseases: the wildlife/ livestock interface. Rev Sci Tech Oie. 2002;21(1):53-65. 
10. Hide G. History of sleeping sickness in East Africa. Clin Microbiol Rev. 1999; 12(1):112-25.

11. Haji IJ, Sugimoto C, Kajino K, Malele I, Simukoko H, Chitambo H, Namangala B. Determination of the prevalence of trypanosome species in cattle from Monduli district, northern Tanzania, by loop mediated isothermal amplification. Trop Anim Health Prod. 2015;47(6):1139-43.

12. Munang'andu HM, Siamudaala V, Munyeme M, Nalubamba KS. A review of ecological factors associated with the epidemiology of wildlife trypanosomosis in the Luangwa and Zambezi Valley ecosystems of Zambia. Interdiscip Perspect Infect Dis. 2012;7(603):1-10.

13. Ellis BR, Wilcox BA. The ecological dimensions of vector-borne disease research and control. Cad Saude Publica. 2009;25(1):155-67.

14. Mboera LEG, Mayala BK, Kweka EJ, Mazigo HD. Impact of climate change on human health and health systems in Tanzania: A review. Tanzan J Health Res. 2011;13(1):1-10

15. Majekodunmi AO, Fajinmi A, Dongkum C, Picozzi K, MacLeod E, Thrusfield MV, Welburn SC. Social factors affecting seasonal variation in bovine trypanosomosis on the Jos Plateau, Nigeria. Parasit Vectors. 2013;6:293.

16. Savić S, Vidić B, Grgić Z, Potkonjak A, Spasojevic L. Emerging vector-borne diseases - incidence through vectors. Front Public Health. 2014;2(267):1-4.

17. Anderson NE, Mubanga J, Machila N, Atkinson PM, Dzingirai V, Welburn SC. Sleeping sickness and its relationship with development and biodiversity conservation in the Luangwa Valley, Zambia. Parasit Vectors. 2015;8:224.

18. Radostits OM, Gay CC, Hinchcliff KW, Constable PD. Veterinary medicine: A textbook of diseases of cattle, horses, sheep, pigs, and goats. 10th ed. New York: Saunders elsevier; 2006.

19. Mohini J, Deshpande JD. Polymerase Chain Reaction: Methods, principles and application. Int J Biomed Res. 2010;1(5):81-97.

20. Cox A, Tilley A, McOdimba F, Fyfe J, Eisler MC, Hide G, Welburn SCAPCR. based assay for detection and differentiation of African trypanosome species in blood. Exp Parasitol. 2005;111:24-9.

21. Thumbi SM, McOdimba FA, Mosi RO, Jung'a JO. Comparative evaluation of three PCR based diagnostic assays for the detection of pathogenic trypanosomes in cattle blood. Parasit Vectors. 2008;1:46.

22. Ahmed HA, Picozzi K, Welburn SC, MacLeod ETA. comparative evaluation of PCR-based methods for species-specific determination of African animal trypanosomes in Ugandan cattle. Parasit Vectors. 2013;6:316.

23. Malele II, Ouma JO, Enyaru JC, Matovu E, Alibu V, Auma JE, et al. Comparative diagnostic and analytical performance of PCR and LAMPbased trypanosome detection methods estimated using pooled whole tsetse flies and midguts. Vet Parasitol. 2013;8:197.

24. AWF: The Maasai Steppe. 2015. http://www.awf.org/landscape/maasai-steppe Accessed 6 Aug 2015.

25. Patz JA, Confalonieri UEC, Amerasinghe FP, Chua KB, Daszak P, Hyatt AD, et al. Human health: ecosystem regulation of infectious diseases. In: Hassan $\mathrm{R}$, Scholes R, Ash N, editors. Ecosystems and human well-being: current state and trends. Washington, DC: Island Press; 2005. p. 391-415.

26. Msoffe FU, Said MY, Ogutu JO, Kifugo SC, Leeuw J, Gardingen P, Reid RS Spatial correlates of land-use changes in the Maasai Steppe of Tanzania: Implications for conservation and environmental planning. Int J Biodivers Conserv. 2011:3(7):280-90.

27. Njiru ZK, Constantine CC, Guya S, Crowther J, Kiragu JM. The use of ITS I rDNA PCR in detecting pathogenic African trypanosomes. Parasitol Res. 2005;95:186-92.

28. Silbermayr K, Li F, Soudré A, Müller S, Sölkner JA. Novel gPCR Assay for the detection of African animal trypanosomosis in trypanotolerant and trypanosusceptible cattle breeds. PLoS Negl Trop Dis. 2013;7(8):1-9.

29. Njiru ZK, Mikosza ASJ, Armstrong T, Enyaru JC. Ndung'u JM, Thompson ARC. Loop-mediated isothermal amplification (LAMP) method for rapid detection of Trypanosoma brucei rhodesiense. PLoS Negl Trop Dis. 2008;2(2):1-8.

30. Swai ES, Kaaya JE. A parasitological survey for bovine trypanosomosis in the livestock/wildlife ecozone of northern Tanzania. Vet World. 2012;5(8):459-64.

31. Goossens B, Mbwambo H, Msangi A, Geysen D, Vreysen M. Trypanosomosis prevalence in cattle on Mafia Island (Tanzania). Vet Parasitol. 2006;139:74-83.

32. Auty H, Torr SJ, Michoel T, Jayaraman TS, Morrison LJ. Cattle trypanosomosis: the diversity of trypanosomes and implications for disease epidemiology and control. Rev Sci Tech. 2015;34(2):587-98.

33. Nzalawahe J. Role of domestic animals in the epidemiology of human African trypanosomosis in Kigoma, Tanzania. MSc Thesis, Sokoine University of Agriculture, Department of Veterinary Medicine and Public Health; 2010.
34. Laohasinnarong D, Thekisoe OM, Malele I, Namangala B, Ishii A, Goto Y, et al. Prevalence of Trypanosoma spp. in cattle from Tanzania estimated by conventional PCR and loop-mediated isothermal amplification (LAMP). Parasitol Res. 2011;109(6):1735-9.

35. Ibrahim B, Ibrahim FN. Pastoralists in transition - a case study from Lengijape, Maasai Steppe. GeoJournal. 1995;36(1):27-48.

36. Voeten MM. Living with wild life: Coexistence of wildlife and livestock in an East African Savanna system. PhD Thesis, Wageningen University and Research Centre; 1999.

37. Franco JR, Simarro PP, Diarra A, Jannin JG. Epidemiology of human African trypanosomosis. Clin Epidemiol. 2014;6:257-75.

38. Geiger A, Cuny G, Frutos R. Two tsetse fly species, Glossina palpalis gambiensis and Glossina morsitans morsitans, carry genetically distinct populations of the secondary symbiont Sodalis glossinidius. Appl Environ Microbiol. 2005:71(12):8941-3.

39. Dennis JW, Durkin SM, Horsley JE, Hamill LC, Anderson NE, MacLeod ET. Sodalis glossinidiusprevalence and trypanosome presence in tsetse from Luambe National Park, Zambia. Parasit Vectors 2014;7:378.

40. Desquesnes M, Dia ML. Mechanical transmission of Trypanosoma congolense in cattle by the African tabanid Atylotus agrestis. Exp Parasitol. 2003;105:22631.

41. Auty H, Anderson NE, Picozzi K, Lembo T, Mubanga J, Hoare R, et al. Trypanosome diversity in wildlife species from the Serengeti and Luangwa Valley ecosystems. PLoS Negl Trop Dis. 2012;6:e1828.

42. Mwandiringana E, Gori E, Nyengerai T, Chidzwondo F. Polymerase chain reaction $(\mathrm{PCR})$ detection of mixed trypanosome infection and blood meal origin in field-captured tsetse flies from Zambia. Afr J Biotechnol. 2012; 11(79):14490-7.

43. Salim B, Bakheit MA, Salih SE, Kamau J, Nakamura I, Nakao R, Sugimoto C. An outbreak of bovine trypanosomiasis in the Blue Nile State, Sudan. Parasit Vectors. 2011:4:74.

44. Balmer O, Stearns SC, Schötzau A, Brun R. Intraspecific competition between co-infecting parasite strains enhances host survival in African trypanosomes. Ecology. 2009;90(12):3367-78.

45. Malele II, Magwisha HB, Nyingilili HS, Mamiro KA, Rukambile EJ, Daffa JW, et al. Multiple Trypanosoma infections are common amongst Glossina species in the new farming areas of Rufiji district, Tanzania. Parasit Vectors. 2011;4: 217.

46. Mohamed-Ahmed MM, Odulaja A. Diel activity patterns and host preferences of Glossina fiscipes fuscipes (Diptera: Glossinidae) along the shores of Lake Victoria, Kenya. Bull Entomol Res. 1997;87:179-86.

47. Okoh KE, Ndams IS, Kogi E, Vajime CG. Catch composition of tsetse flies (Glossina: Glossinidae). Am J Appl Sci. 2011;8(11):1067-72.

48. Hargrove JW, Langley PA. Sterilizing tsetse Diptera: Glossinidae in the field: a successful trial. Bull Entomol Res. 1990;80(4):397-403.

49. Torr SJ, Hargrove JW. Behaviour of tsetse (Diptera: Glossinidae) during the hot season in Zimbabwe: The interaction of micro-climate and reproductive status. Bull Entomol Res. 1999:89:365-79.

50. Malele II, Ouma JO, Nyingilili HS, Kitwika WA, Malulu DJ, Magwisha HB, Kweka EJ. Comparative performance of traps in catching tsetse flies (Diptera: Glossinidae) in Tanzania. Onderstepoort J Vet Res. 2016;83(1):1-7.

51. Sindato C, Malele II, Mwalimu C, Nyingilili HS, Kaboya S, Kombe E, et al. Seasonal variation in human African trypanosomiasis in Tarangire National Park in Babati district, Tanzania. Tanzan Health Res Bull. 2007;9:136-9.

52. Kubi C, Van Den Abbeele J, Dorny P, Coosemans M, Marcotty T, Van Den Bossche P. Arthropod-host interaction, immunity: Ability of trypanosomeinfected tsetse flies (Diptera: Glossinidae) to acquire an infection with a second trypanosome species. J Med Entomol. 2005;42(6):1035-8. 